\title{
FESTA DE NOSSA SENHORA DO ROSÁRIO: TERRITORIALIDADE, CULTURA E TRADIÇÃO NO MUNICÍPIO DE SILVIANÓPOLIS-MG ${ }^{1}$
}

\section{FEAST OF OUR LADY OF THE ROSARY: TERRITORIALITY, CULTURE AND TRADICION IN THE CITY OF SILVIANÓPOLIS-MG}

\author{
Jhonatan da Silva CORRÊA ${ }^{2}$ \\ Flamarion Dutra ALVES ${ }^{3}$
}

\begin{abstract}
Resumo: A Festa de Nossa Senhora do Rosário em Silvianópolis-MG ao longo do espaço-tempo apresentou diversos conflitos em sua estrutura, sendo um deles relacionado ao catolicismo popular e oficial e seus simbolismos. Além do mais, há na festividade uma diversidade de públicos, constituindo diferentes territorialidades, propiciando grande disparidade e mutação no cerne festivo. Para o desenvolvimento da pesquisa foi essencial uma revisão historiográfica e bibliográfica da manifestação cultural, existente desde 1780 no município, trabalhos de campo, observações e entrevistas semi estruturadas ocorreram no decorrer da metodologia. $\mathrm{O}$ objetivo da pesquisa esteve relacionado à compreensão das territorialidades e dos processos históricos circunscritos a festividade com o intuito de entender sua dinâmica organizacional, estrutural e de poder emanado no lugar. Portanto, trabalhando conforme ensinado pela geógrafa Rosendahl (2003) os espaços sagrados e profanos em suas dimensões: política, econômica e do lugar.
\end{abstract}

Palavras-chave: Lugar; Poder; Religião; Ruralidade; Território.

\begin{abstract}
The Feast of Our Lady the Rosary in Silvianópolis-MG in over time it presented several conflicts in its structure, one of which is related to popular and oficial catholicism and its symbolisms. In addition, there is a diversity of audiences in the festivity, constituting diferente territorialities, providing great disparity and mutation in the festive core. For the development of the research, a historiographic and bibliographic review of the cultural manifestation, existing since 1780 in the municipality, was essential, fieldwork, observations and semi-structured interviews took place throghout the methodology. The objective of the research was related to the understanding of terrialities and historical processes linked to festivity in order to understand its organizational, structural and power dynamic emanating from its political, economic and place dimensions. Therefore, working as taught by geographer Rosendhal (2003) the sacred and profane spaces in their political, economic and place dimensions.
\end{abstract}

Keywords: Place; Power; Religion; Rurality; Territory.

\footnotetext{
${ }^{1}$ O presente trabalho foi realizado com apoio da Coordenação de Aperfeiçoamento de Pessoal de Nível Superior - Brasil (CAPES).

${ }^{2}$ Mestrando em Geografia pelo Programa de Pós-graduação em Geografia da UNIFAL-MG, bolsista Capes, integrante do Grupo de Estudos Regionais e Socioespaciais (GERES) da UNIFAL-MG e Núcleo de Estudos e Pesquisa Sobre Espaço e Cultura (NEPEC) em rede da UERJ. jhonatan.correa@ sou.unifal-mg.edu.br

${ }^{3}$ Doutor em Geografia pela UNESP - Rio Claro e Professor Associado II do Programa de Pós-graduação em Geografia da UNIFAL-MG e Programa de Pós-graduação em Geografia da UFSJ, Líder Do Grupo de Estudos Regionais e Socioespaciais (GERES) da UNIFAL-MG. flamarion.dutra@ unifal-mg.edu.br
} 


\section{Introdução}

O município de Silvianópolis onde ocorre desde 1780 a tradicional Festa de Nossa Senhora do Rosário, está localizado no Sul do estado de Minas Gerais, conforme mostra a figura 1, e possuía uma estimativa de 6.248 habitantes para o ano de 2020 (IBGE, 2020).

Figura 1 - Localização do Município de Silvianópolis.

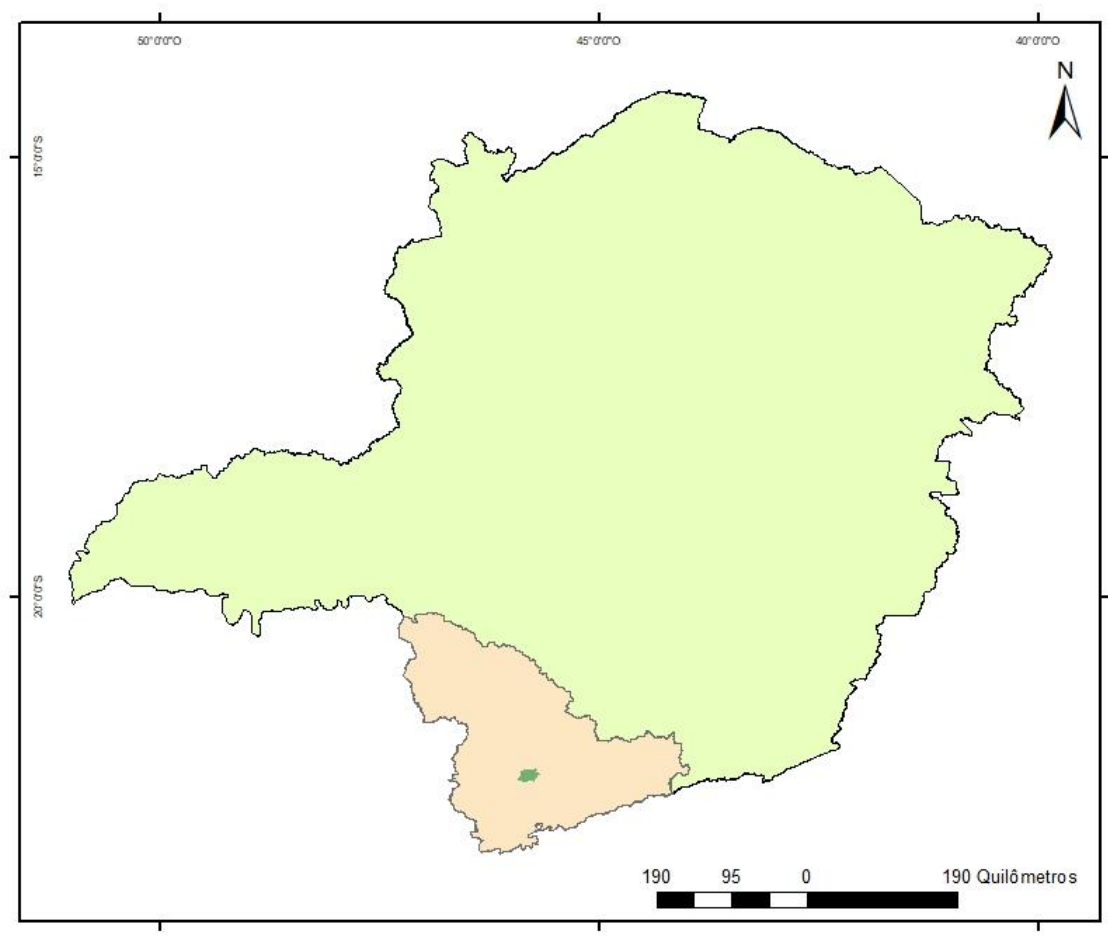

Projeção: UTM

DATUM: SIRGAS 2000

$F: 23 S$

Fonte: IBGE

Legenda

Minas Gerais

Sul de MG

Silvianópolis

\section{Localização do Município de Silvianópolis}

Fonte: Organizado pelos autores em julho de 2020.

De acordo com o IBGE (1959) inicialmente foi constituído o distrito com a toponímia de Santana do Sapucaí no ano de 1832. Posteriormente, elevado à categoria de município: “A 'Divisão Administrativa, em 1911' apresenta constituído dos distritos de Silvianópolis e Dourados o município de Silvianópolis, cuja sua instalação se deu em 1. e junho de 1912" (IBGE, 1959, p. 321). Para mais, a toponímia Silvianópolis é uma homenagem ao nativo Francisco Silviano de Almeida Brandão, médico e político que trabalhou em cargos administrativos no estado de Minas Gerais, inclusive chegou ao posto de Presidente do estado. Posteriormente, atingiu a função de vice-presidente da república no ano de seu falecimento em 1902 (IBGE, 1959). 
EM

A gênese da Festa de Nossa Senhora do Rosário ocorreu por volta do ano de 1780 e tradicionalmente tem a sua realização no mês de junho, mais precisamente no dia $13 \mathrm{em}$ diante (DOMINGUES, 2011). Após o levantamento do mastro é no último final de semana de junho onde ocorrem as principais manifestações e há o maior fluxo de participantes e visitantes na festividade. A manifestação cultural tem como principal santa, referente ao catolicismo popular, Nossa Senhora do Rosário. No entanto, São Benedito e Santa Efigênia estão presentes nas manifestações culturais e nas homenagens dos congadeiros e do público presente. $\mathrm{Na}$ origem da organização festiva havia um elo entre o catolicismo oficial e sua realização, onde o intuito era controlar e catequizar os escravizados que ali estavam situados:

A permissão era dada, visando diminuir as forças: o negro, existindo como constante ameaça ao potentado, não só para ser em número maior, como também, pela possibilidade de criar redutos em forma de quilombos, que se expandiram por todas as Minas Gerais até a segunda metade do século XIX, à primeira força, o medo dessa ameaça desapareceria quando se permitia ao extravasamento de tensões por meio das festas ou, outras vezes, mais constantes neste, o senhor destruía a força do negro sob a chibata, tronco e outras formas piores de suplícios; quanto à segunda força de ameaça, uma reunião de Quilombo podia ser evitada, desse modo, pensava, se permitisse aos negros se reunisse às suas visitas através do Reinado, evitando, desse modo, que eles fossem procurar o Reinado real dos aquilombados. (SOUZA, 2015(a), p. 106).

No decorrer do espaço-tempo houve o rompimento com o catolicismo oficial, a festa de outrora realizada para controlar e dominar hoje possui outras características se inserindo no catolicismo popular e sendo organizada por membros não eclesiásticos, entendidos como leigos pela estrutura presente na hierocracia do catolicismo oficial (CORRÊA, 2019; DOMINGUES, 2011). Como consequência, houve e ainda há conflitos entre a vertente oficial e popular do catolicismo resultando na disputa do poder sobre a territorialidade festiva. Domingues (2011) mostrou diversas investidas do catolicismo oficial perante o domínio popular da festa. Para deixar a territorialidade mais complexa, além do conflito entre os catolicismos, hodiernamente, há presença dos barraqueiros ${ }^{4}$ e a sua complementação na dinâmica territorial da festa pode se dar de forma conflituosa.

A presente pesquisa está em andamento, sendo parte de uma dissertação sobre a manifestação das festas de congo no Sul de Minas Gerais. Devido a importância de Silvianópolis no cenário cultural religioso da região, há um olhar específico para as

\footnotetext{
${ }^{4}$ Vendedores efêmeros que se estabelecem no município durante o período de festa. 
EM

QUESTÃO

particularidades da ocorrência festiva no município. Portanto, o intuito do texto é trazer inquietações e os resultados iniciais da pesquisa.

Para mais, o objetivo estabelecido foi de interpretar as territorialidades e os processos históricos e geográficos circunscritos na festividade com o intuito de entender a dinâmica política, econômica e do lugar (ROSENDAHL, 2003). Além de buscar a compreensão dos conflitos entre a igreja católica oficial e as manifestações populares ligadas ao catolicismo popular na formulação da Festa de Nossa Senhora do Rosário. Esses são alguns pontos que norteiam o trabalho e seu avanço, deixando com sua consolidação uma contribuição não somente para a Festa de Nossa Senhora do Rosário em Silvianópolis, mas também para todo cenário cultural do Sul de Minas Gerais.

\section{Procedimentos adotados}

Para o avanço da pesquisa foi indispensável inicialmente a realização de uma revisão bibliográfica e historiográfica com o intuito de entender a dinâmica e a transformação festiva de acordo com o espaço-tempo. Para tanto, foram consultados livros, artigos e a Associação de Caridade Nossa Senhora do Rosário de Silvianópolis. Ademais, a revisão não ocorreu exclusivamente no âmbito histórico, mas também conceitual, buscando um melhor entendimento sobre os principais conceitos basilares da pesquisa.

Em um segundo momento, os trabalhos de campo fizeram-se presentes nos anos de 2018 e 2019, formulando outro procedimento imprescindível para a pesquisa. Nesse momento, a observação foi importante para isolar e trabalhar sobre os acontecimentos festivos. Segundo Malinowski (1975) a observação tem como característica a capacidade de selecionar, classificar e isolar através de uma teoria elementos importantes para pesquisa.

A geógrafa Rosendahl (2012b) mostrou a importância do trabalho de campo como um instrumento metodológico, pois através dele o pesquisador consegue adquirir dados etnográficos relacionados a religiosidade do lugar, manifestada pelo homem religioso em um dado espaço e tempo. Ademais, além das observações presentes nos trabalhos de campo, para a constituição dos dados foram realizadas entrevistas com a população festiva sendo 52 no total.

O público entrevistado é diverso, dos 52 entrevistados; $52 \%$ eram moradores do município de Silvianópolis, $46 \%$ eram moradores de outros municípios e 2\% moravam em 
EM

QUESTÃO

V.14 N. $02 \downarrow 2021$

pág. $185-205$

Silvianópolis e outros municípios. Na aplicação das entrevistas houve a preocupação de buscar uma diversidade de público, aplicando em faixas etárias diferenciadas como adolescentes, jovens, adultos e público mais idoso. Para uma melhor representatividade também as entrevistas foram realizadas com intuito de abarcar tanto homens como mulheres. Essa disparidade ficou estabelecida de acordo com as oportunidades reveladas no campo. Para mais, as entrevistas foram realizadas de forma semi estruturada, onde: "o entrevistador segue um determinado número de questões principais e específicas, em uma ordem prevista, mas é livre para incluir outras questões" (LIMA, 2006, p.27). Logo, durante as aplicações novas interrogações se constituíam tornando a abordagem mais dinâmica.

Cada entrevista realizada teve uma duração média de 5 minutos com a população festiva. Além disso, foram efetuadas outras entrevistas no período não festivo com duração média de 50 minutos direcionadas aos congadeiros e festeiros do município. $\mathrm{O}$ intuito foi entender o ser histórico e sua essência, bem como o lugar e suas representações relacionadas às divergências sociais, conflituais e territoriais. Questões presentes na ontologia contemporânea, onde o ser-no-mundo, a subjetividade e a geograficidade são trabalhadas (HOLZER, 2010). A escolha da entrevista ocorreu pelo fato de possibilitar o acesso à memória, as lembranças e as experiências de cada entrevistado, buscando compreender sua relação com o lugar e o território no qual se encontra (LIMA, 2006, p.26).

\section{Entre conceitos: uma reflexão em análise}

Entender como a geografia interpreta os aspectos religiosos e culturais, para a compreensão da Festa de Nossa Senhora do Rosário em Silvianópolis se faz necessário:

A abordagem da religião vem impondo reflexões sobre a experiência dos indivíduos e dos grupos sociais na construção de espaços fortemente vinculados ao sagrado. [..]. Os estudos exemplificam as relações entre espaço e religião, nas quais dois pontos são fundamentais na interpretação: sagrado e profano (ROSENDAHL, 2012b, p.25).

Segundo a geógrafa Rosendahl (1999) o espaço sagrado está relacionado a regência guiada pelo simbolismo religioso; em contrapartida, o espaço profano é privado de sacralidade e se mantém ligado ao espaço sagrado. Há, portanto, uma simbiose presente na relação. Através da manifestação do sagrado há alteração no espaço vivido, causando a ruptura do habitual em um determinado tempo e espaço, transformando a estruturação profana 
e permitindo a emanação das hierofanias nos lugares sacros (ELIADE, 1962; ROSENDAHL, 2002).

Para Oliveira (2019) a geografia se enraíza na abordagem religiosa possuindo como inquietação o questionamento espacial da religião e toda sua modificação estrutural do espaço por meios religiosos emanados de diversas práticas devocionais. Sendo assim:

Ainsi la Géographie humaine, quia por but spécial d'étudier les différents aspects de cet effort humano, doid rendre compte de la part de ce labeur qui est marquée du signe religieux; il y a donc nécesariament une section de la Geographie humaine qui s'apelllera Géographie des Religiones ${ }^{5}$ (DEFFONTAINES, 1948, p. 8).

Além disso, na abordagem religiosa as festas relacionadas ao sagrado e ao profano como a de Silvianópolis estão ligadas às práticas do catolicismo popular brasileiro. Esse catolicismo se manifestou devido à existência de um conjunto de fatores relacionados à história e à consolidação territorial do país. A dinâmica organizacional existente no catolicismo popular provocou e provoca um deslocamento cultural, hegemônico e histórico do modo de sentir o sagrado, outrora sobre a égide do catolicismo oficial (FREYRE, 2000; RIBEIRO, 2015; ROSENDAHL, 2012(a)).

O homem em sua atuação social transforma o espaço formulando culturas díspares, podendo através de sua consolidação constituir o lugar. "Por meio da habilidade humana, a natureza é transformada em objetos culturais. [..]. As representações de mundo são construídas na produção desses objetos culturais que, reunidos no tempo e no espaço, transformam a paisagem em lugar" (LUCHIARI, 2001, p. 22).

Sendo assim, o conceito de lugar ganha importância na discussão para o avanço da pesquisa. O lugar trabalhado não representa uma localidade, contudo, possui como característica espacial ser dotado de elementos simbólicos possuidores de significados ambivalentes: hospitaleiro para alguns e ruim e perigoso para outros (SOUZA, 2015b). "O lugar é um mundo significado organizado.” (TUAN, 2013, p. 219). Portanto, o lugar pode ser entendido como pausa e o espaço como movimento (TUAN, 2013).

\footnotetext{
5 Tradução dos autores: “Assim, a Geografia Humana, que tem o objetivo especial de estudar os diferentes aspectos do esforço humano, deve explicar parte desse trabalho que é marcado pelo sinal religioso; existe, portanto, necessariamente uma seção da Geografia Humana que será chamada Geografia das Religiões".
} 
EM

A ciência geográfica pressupõe que o mundo seja conhecido geograficamente, que o homem se sinta e se saiba ligado à Terra como ser chamado a se realizar em sua condição terrestre. [..] A realidade geográfica é para o homem, então, o lugar onde ele está, os lugares de sua infância, o ambiente que atrai sua presença. Terras que ele pisa ou onde ele trabalha, o horizonte de seu vale, ou a sua rua, seu bairro, seus deslocamentos cotidianos através da cidade (DARDEL, 2015, p. 34).

Outra questão subsequente ao espaço e de grande importância para o desenvolvimento epistêmico, científico e material da pesquisa é o território e suas derivações. Destarte, o território é compreendido pela sua relação desigual de forças, onde envolve a subordinação tanto política como econômica do espaço. Por isso não há somente nele a manipulação dos aspectos físicos, mas também das questões sociais (HAESBAERT, 2006).

Ademais, o território é importante para perpetuação social de um povo, não existindo um grupo social ou etnia que no ato de sua existência não tenha investido na formulação de um território de forma direta ou indireta (BONNEMAISON, 2002). Como consequência: “[..] o território é um importante instrumento de existência e da reprodução do agente social que o criou e o controla. Apresenta além do caráter político um nítido caráter cultural especialmente quando os agentes sociais são grupos étnicos, religiosos ou de outras identidades" (ROSENDAHL, 2013, p. 174).

O território se produz através das relações de poder, é um local onde se tem a projeção do trabalho, da energia e informação. A produção, troca e consumo existente no território é o que caracteriza a territorialidade. Todo sistema territorial possui sua territorialidade, ou seja, a territorialidade é inerente ao território (RAFFESTIN, 1993). Para mais, há nas territorialidades continuidades e descontinuidades situadas no tempo e no espaço. As territorialidades possuem uma ligação com o lugar, estabelecendo sua identidade e formalizando parâmetros perante sua condição histórica e geográfica de cada lugar (SAQUET, 2015). Na territorialidade religiosa não é diferente:

A territorialidade religiosa por sua vez, significa o conjunto de práticas desenvolvidas por instituições ou grupos no sentido de controlar certo território, onde o efeito do poder do sagrado reflete uma identidade de fé e um sentimento de propriedade mútuo. A territorialidade é fortalecida pelas experiências religiosas coletivas ou individuais que o grupo mantém no lugar sagrado e nos itinerários que constituem seu território (ROSENDAHL, 2013, p. 176).

Desta forma, nas territorialidades festivas acontecem as relações onde o poder se manifesta resultante de dois polos que se fazem face a face ou que estejam em discordância 
EM

QUESTÃO

criando o campo do poder definido como uma combinação de energia e informação, visando o controle e a dominação de uma situação (RAFFESTIN, 1993). O poder deve ser analisado e compreendido como algo que circula, funcionando em rede (FOUCAULT, 2017). Ainda de acordo com Foucault (2017) o exercício do poder se dá através da ação; em um instante o exercendo e em outro sofrendo suas consequências. O poder não é estático e não há como retê-lo, os atores sociais funcionam como um centro transmissor, ele está presente em toda camada social.

Prossigamos, os itinerários simbólicos estão situados em um tempo qualitativo, constituem um momento de ruptura temporal e espacial acentuados pelos simbolismos de uma determinada cultura presentes em seu cerne, portanto sendo regido principalmente pelo tempo Kairológico (CORRÊA, 2012; ROSENDAHL, 2018). Além do mais, o que caracteriza um itinerário simbólico é a sua necessidade de reatualização, podendo acontecer em uma data estabelecida anualmente rompendo com o cotidiano e se revelando em elementos religiosos ou não (CORRÊA, 2012).

Segundo Claval (2014) essas rupturas tanto espaciais como temporais é o que caracteriza uma festa onde se tem a necessidade da transcendência configurada como inversão social e catarse para sua consolidação temporal e espacial. Por último, cabe destacar a questão econômica da festa, pois é nítido esses espaços comerciais ou profanos relacionados de forma direta ou indireta com espaço sagrado (ROSENDAHL, 2006). Logo, o presente trabalho visa uma abordagem que consiga abranger os aspectos econômicos, políticos e do lugar (ROSENDAHL, 2003).

\section{A festa popular: entre territorialidades, conflitos e ruralidades}

A Festa de Nossa Senhora do Rosário em Silvianópolis possui diferentes conflitos em sua composição, uma das contendas está relacionada às duas vertentes do catolicismo. A historiadora Domingues (2011) mostrou o triste episódio da destruição da Capela de Nossa Senhora do Rosário, no início do século XX, ordenada por um membro eclesiástico. Posteriormente ao momento supracitado houve a construção da Casa Santa, presente na fotografia 1, através do esforço de populares, sendo até o atual momento conduzida e cuidada pela Associação de Caridade Nossa Senhora do Rosário de Silvianópolis. Em contrapartida, a igreja central do município pertence à arquidiocese de Pouso Alegre-MG. 
EM

QUESTÃO

V.14 N. $02 \downarrow 2021$

pág. 185-205

Fotografia 1- Lugares sagrados do catolicismo popular e oficial em Silvianópolis-MG.

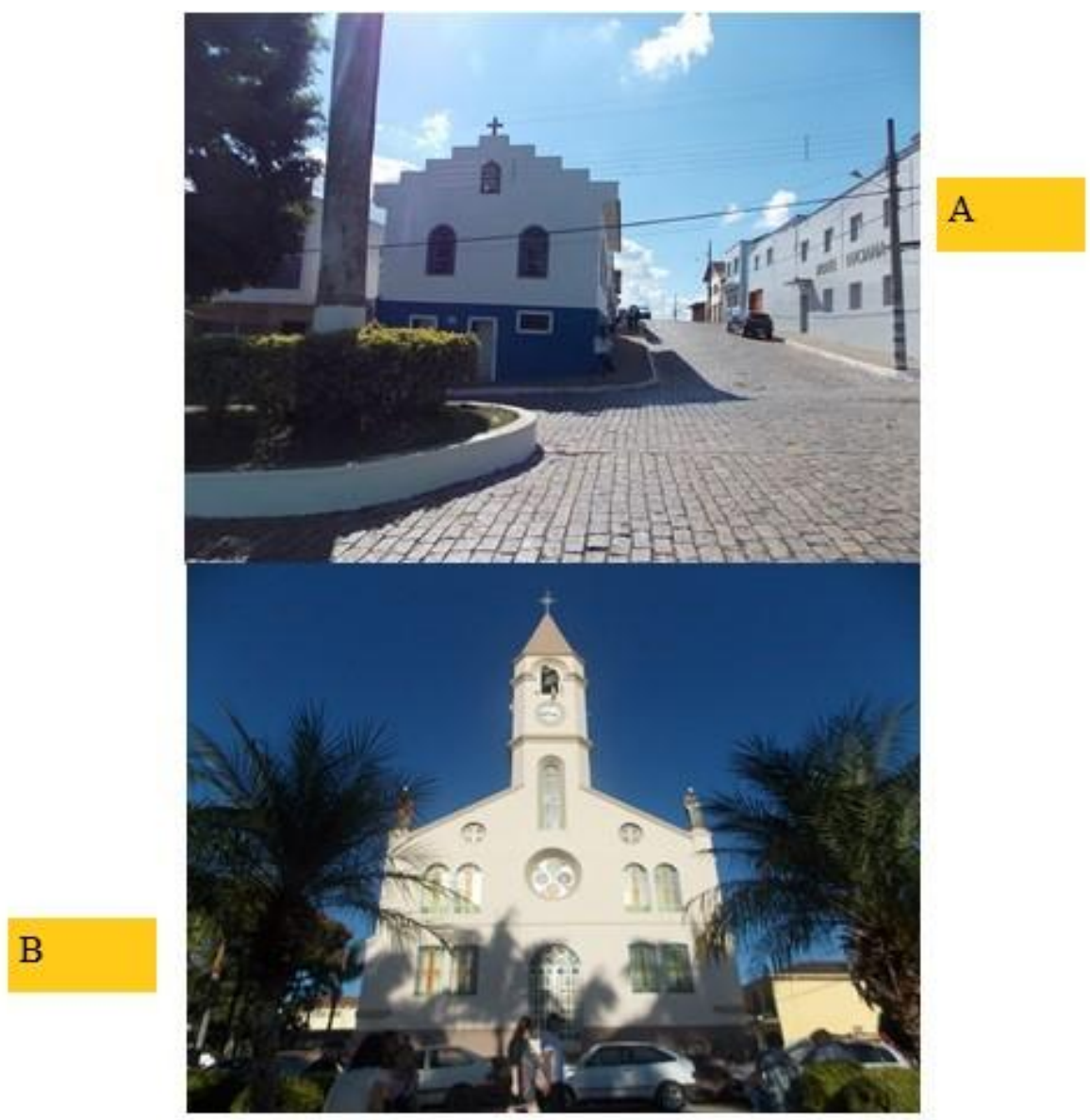

A) Casa Santa-Capela de Nossa Senhora do Rosário em Silvianópolis-MG.

B) Igreja de Sant'Ana em Silvianópolis-MG.

Fonte: Acervo particular dos autores (Junho de 2019).

É compreensível na fotografia 1 como a territorialidade ligada ao sagrado constitui, acentua e materializa as disparidades organizacionais dos catolicismos. A capela de Nossa Senhora do Rosário representa o catolicismo popular brasileiro, é administrada por leigos, ou seja, membros não eclesiásticos. Já a paróquia de Sant'Ana, criada em 1748 é administrada por membros eclesiásticos possuindo elo com o catolicismo oficial romanizado e inserida em uma hierocracia ${ }^{6}$. Sendo assim, há na cidade duas santas padroeiras: Nossa Senhora do Rosário ligada ao catolicismo popular e Sant'Ana referente ao catolicismo oficial.

A Igreja de Sant'Ana mantém suas portas fechadas durante grande parte da festividade, abrindo-as poucas vezes para os ternos de congo, população e visitantes durante os dias festivos. Para Domingues (2011) a participação dos membros eclesiásticos na festa está atribuída a quem estiver à frente da igreja, podendo o conflito ser atenuado em alguns momentos e mais agitado em outros.

\footnotetext{
${ }^{6}$ Ordem hierárquica eclesiástica. 
EM

QUESTÃO

V.14 N. $02 \downarrow 2021$

pág. $185-205$

A festa popular resiste sendo organizada exclusivamente pela população do município, é uma festa realizada por membros não eclesiásticos onde os festeiros são escolhidos pela Associação de Caridade Nossa Senhora do Rosário de Silvianópolis. Após a escolha há um ano para a arrecadação de fundos, as "esmolas" como são chamadas, recolhidas tanto na cidade como na zona rural do município, podendo ser doado dinheiro ou alimento. Essa divisão entre catolicismo popular e oficial encontra-se longe de fenecer, a igreja oficial já tentou em outras ocasiões entrar para a organização festiva, o que foi negado pelos moradores do município (DOMINGUES, 2011; CORRÊA, 2019).

Além do mais, outros conflitos também recorrentes estão entre o espaço destinado à cultura e a parte referente às atividades econômicas da festividade. Na rua Bocaiúva e R. Manoel Ferreira Vilhena ${ }^{7}$ há constantes fluxos de automóveis durante a manifestação do itinerário simbólico o que pode vir a ser um problema devido ao iminente risco de acidente. $\mathrm{Na}$ rua Edmundo Carneiro e rua Major Feliciano ${ }^{8}$ o cortejo chega a dividir espaço com as barracas onde se tem a comercialização principalmente de comidas e bebidas, também há espaço destinado ao lazer para crianças, conforme mostra a figura 2.

Figura 2 - Itinerário simbólico durante a Festa de Nossa Senhora do Rosário, Silvianópolis.

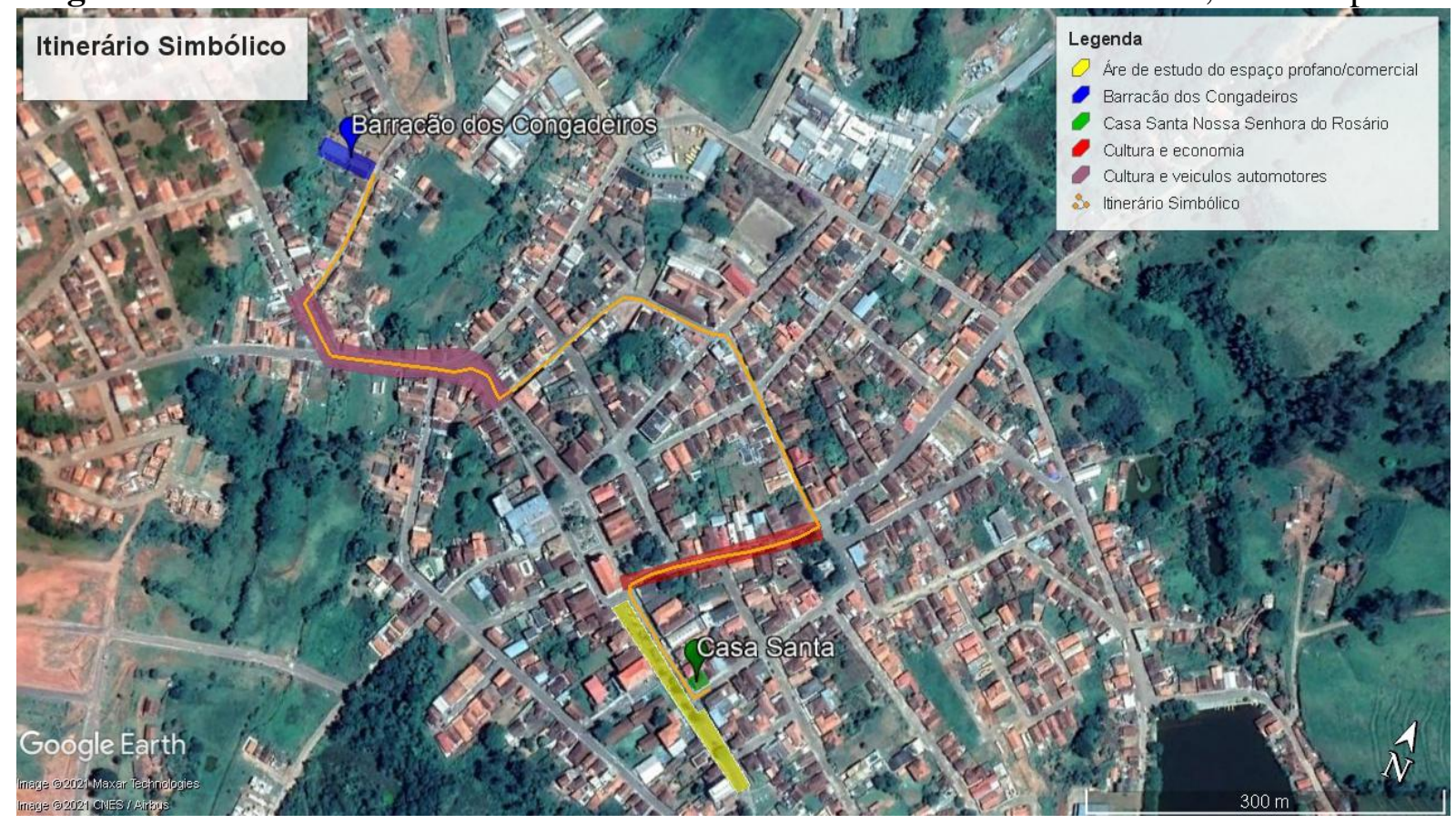

Fonte: Google Earth, 2019, organizado pelos autores, agosto de 2019.

\footnotetext{
${ }^{7}$ Delimitado de roxo na Figura 2.

${ }^{8}$ Delimitado de vermelho na Figura 2.
} 
EM

QUESTÃO

As territorialidades e os conflitos mostrados na figura 2 destacam o caminho percorrido pelos itinerários simbólicos, saindo do barracão dos Congadeiros com destino à Casa Santa ${ }^{9}$. No Caminho foram encontradas tensões territoriais ora entre motoristas de veículos automotores e a manifestação cultural; ora com a parte econômica e a cultural. Por conseguinte, o espaço fica reduzido e os ternos de congadas ${ }^{10}$, moçambiques ${ }^{11}$ e caiapós ${ }^{12}$ podem possuir dificuldades de locomoção, fazer seus rituais e evoluções. A população festiva acompanha o festejo contribuindo para o encolhimento do espaço, mas proporcionando um mutualismo de alegria e hierofanias ${ }^{13}$ no espaço sagrado. "[..] Cada um é ao mesmo tempo ator e espectador e vive um momento de intensa emoção, comunhão e evasão. O sentimento do pertencimento coletivo é, então, muito forte" (CLAVAL, 2014, p. 139).

Fotografia 2 - Séquito do Reinado e o conflito espacial com as barracas e áreas de lazer.
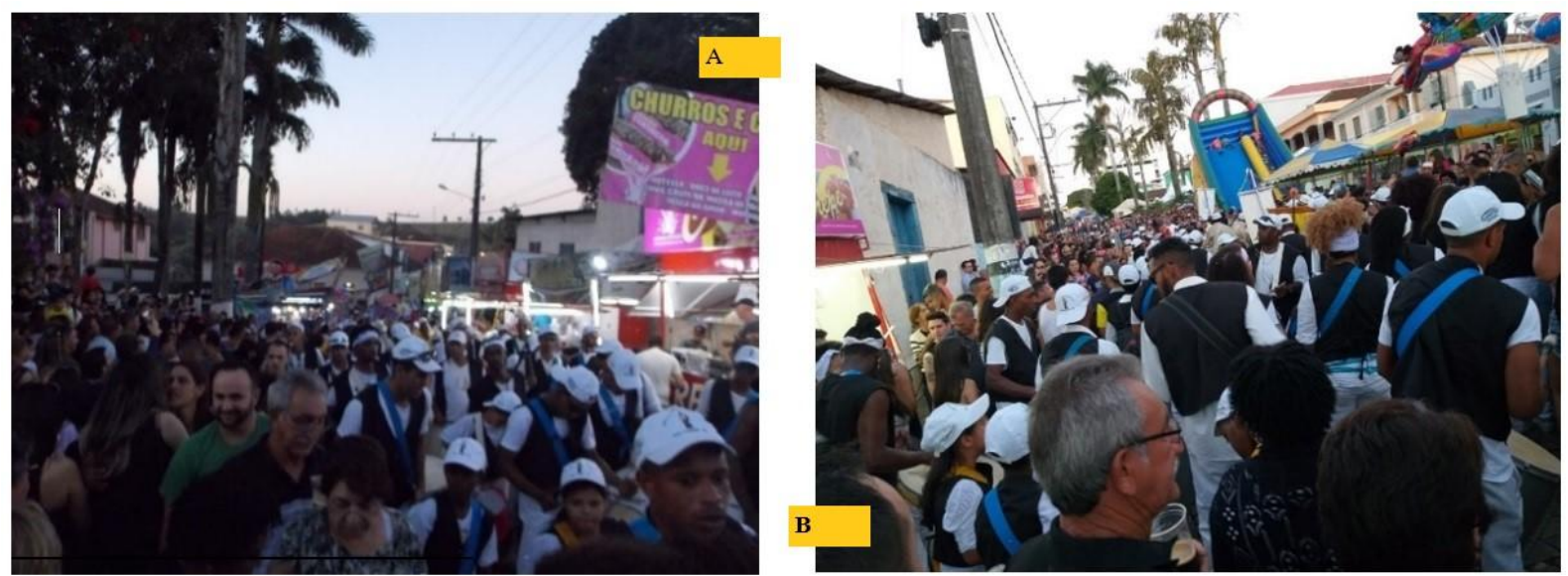

A) Disputa por espaço dos ternos e barracas.

B) Disputa por espaço dos ternos e áreas de lazer.

Fonte: Acervo particular dos autores (junho de 2019).

Na Festa de Nossa Senhora do Rosário apesar do conflito supracitado não chega a ocorrer a expulsão paulatina dos agentes culturais, como ocorreu na Festa de São Benedito em Machado-MG (CORRÊA e ALVES, 2017). Em Silvianópolis por ser uma festa popular e deveras organizada por membros não eclesiásticos, possui maior unicidade na gestão. Logo, não se tem um cenário de atravanque à manifestação cultural e sim uma redução espacial.

\footnotetext{
${ }^{9}$ Capela de Nossa Senhora do Rosário.

${ }^{10}$ Possui batidas mais harmoniosas e ritmadas, podem possuir números maiores de integrantes.

11 São grupos menores com sonoridade mais contida e prioridade na condução do séquito religioso.

${ }^{12}$ Homenagem aos índios por sua contribuição na luta contra o potentado, sonoridade constituída por poucos instrumentos.

${ }^{13}$ Manifestação do Sagrado.
} 
EM

Entende-se conflito como consequência da divergência de interesses de determinados grupos sociais, há em seu cerne tensões e desentendimentos (GIDDENS E SUTTON, 2016). Os conflitos podem ocorrer por inúmeras ocasiões, podendo ser eles por motivos econômicos, étnicos, históricos, sociais, religiosos, entre outros (LEMOS, 2021). De acordo com Arendt (2007) é intrínseco do humano o potencial político com caráter díspar existente no âmago da convivência. Logo, o conflito se faz presente na vida e nas relações dos indivíduos em sociedade.

Ademais, outro conflito presente na territorialidade está relacionado ao sincretismo, a festa possui Nossa Senhora do Rosário como Santa padroeira da festividade. Há na manifestação festiva por meio dos ternos de Congadas, Caipós e Moçambiques uma herança pautada no sincretismo religioso e, por isso, sendo possível a manifestação de diversas vertentes religiosas como a católica, a umbanda, o candomblé, entre outras que podem compor a manifestação popular do catolicismo. O sincretismo está associado diretamente com a história de cada terno, por isso há grande variabilidade na composição. "O catolicismo é uma forma específica da religiosidade popular e o catolicismo popular representa uma forma específica do catolicismo. Este por sua vez é um conjunto aculturado da fé que, no catolicismo popular sofre uma "segunda tradução", uma aculturação específica de camada" (SÜSS, 1979, p. 47).

As Congadas, as danças, as músicas, as vestimentas e os rituais, a população do lugar e o culto às raízes indígenas, durante o espaço e tempo festivo constituem as rupturas para a consolidação festiva, conforme mostra a fotografia 3. Essas rupturas podem conter em suas representações a pacificidade, como de praxe, ou adentrar em algumas rivalidades de ternos podendo ocasionar brigas e discussões.

$\mathrm{Na}$ fotografia 3 é possível observar a diversidade existente na forma de cultuar e sacralizar o tempo e o espaço. O ambiente festivo lembra bem o tempo da roça, onde as comidas são feitas no fogão a lenha trazendo recordações. Quando entrevistado um exfesteiro, foi externalizado por ele que o dinheiro arrecadado para a organização festiva é gasto principalmente com comida, congadas e foguetes. Segundo Leers (1977) as festas advindas do meio rural possuem como característica o uso de foguetes em seus momentos comemorativos. 
Fotografia 3 - Representações culturais do sincretismo da Festa de Nossa Senhora do Rosário, Silvianópolis - MG.
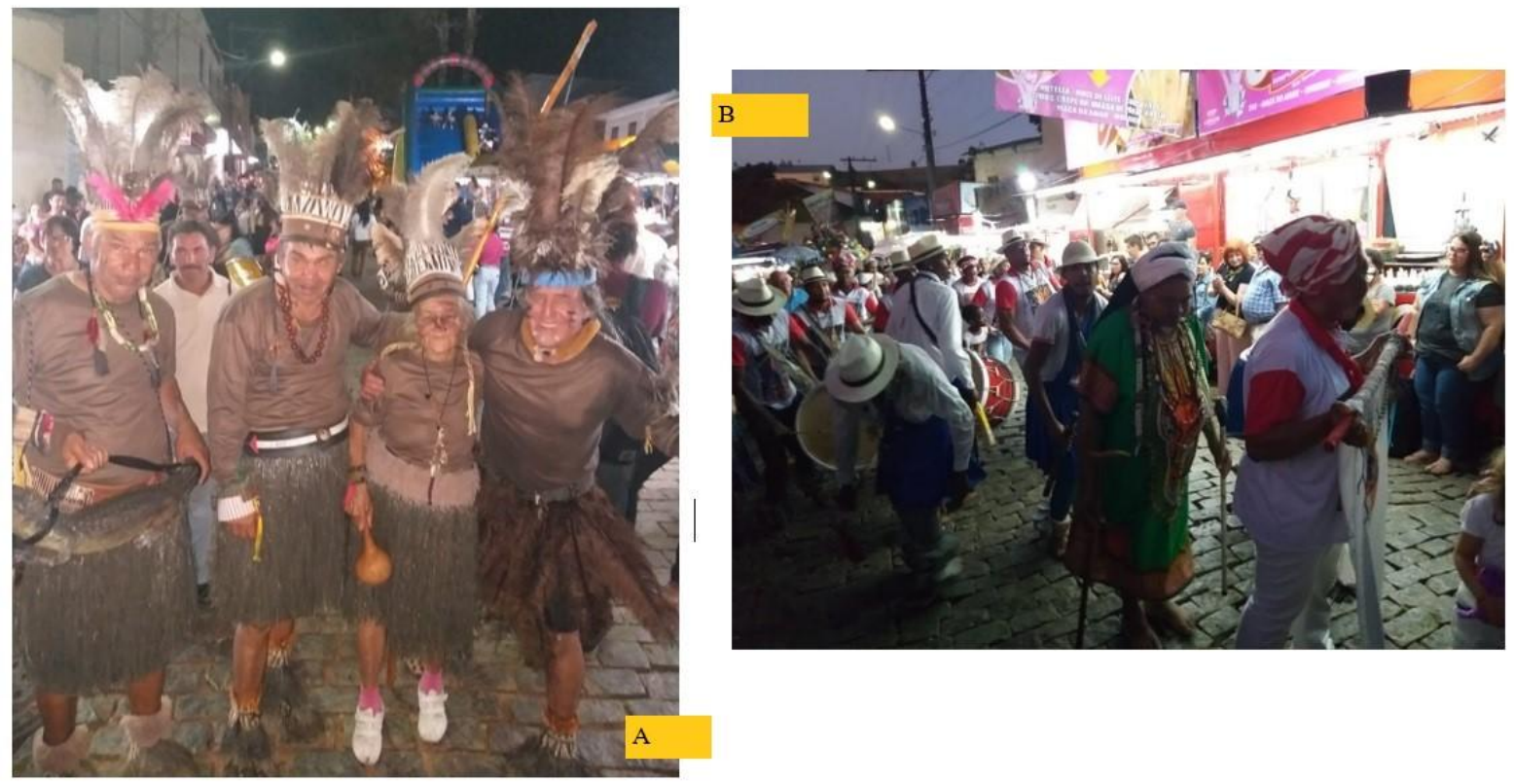

A) Terno de Caiapó se apresentando na festa.

B) Terno de Moçambique se apresentando na festa.

Fonte: Acervo particular dos autores (junho de 2019).

De acordo com Alves (2018) essas características encontradas no contexto citadino expressam as ruralidades do lugar. Neste caso, se materializam através das manifestações efêmeras e nostálgicas situadas em um determinado tempo e espaço (CORRÊA e ALVES, 2020). "Ela me faz lembrar muito o tempo da roça, eu vivo na roça. Ela me faz lembrar um tempo de fartura, um tempo abençoado, um tempo que você esquece as tristezas e é só alegria" (SOUZA, Benedito Felipe de ${ }^{14}$ ). Além do mais, o contexto histórico não é esquecido: "Na verdade a gente tenta lembrar como era antigamente. A gente tenta lembrar isso, como era na senzala antigamente, todo mundo junto, unido". (VIANA, Karolyne ${ }^{15}$ e VIANA, Maria Helena ${ }^{16}$ )

As maiores doações vêm do leite com café. Aí então mistura, o cara fala: ah, vou lá ver meu funcionário na congada. O outro vai lá porque quer comer o doce de abóbora que eles fizeram e a comida no tacho que lembra o fogão a lenha lá na roça; quero comer aquela comida lá, que hoje está sendo feita somente no fogão a lenha. Aí chega lá, aquelas panelonas, lembram lá os nossos pais (SILVEIRA, Wagner Sebastião $0^{17}$ ).

\footnotetext{
${ }^{14}$ Congadeiro há décadas no município de Silvianópolis - [agosto de 2018].

${ }^{15}$ Jovem congadeira do município de Silvianópolis - [Setembro de 2018].

${ }^{16}$ Guarda coroa do município de Silvianópolis - [Setembro de 2018].

${ }^{17}$ Festeiro na Festa de 2018 - Silvianópolis - [Agosto de 2018].
} 
EM

Para a festividade ser longínqua a perpetuação cultural é muito importante, para estimular e formalizar o lugar e a geograficidade das pessoas que estão ligadas a ela. Para Bosi (1986) a cultura popular se constitui por meio da educação informal, essa educação caminha paralelamente à educação formal. São através dos conhecimentos advindos da educação informal que a cultura popular é irrigada. No município de Silvianópolis a manifestação popular das congadas e da festividade são (re)passadas pela oralidade e são os dois ternos da cidade responsáveis pela perpetuação das congadas para as novas gerações, a alimentação também é um rito temporal e espacial importante para a constituição festiva onde a oralidade se faz um meio farto para sua continuação.

\section{O público festivo e suas diferenças}

O público presente na Festa de Nossa Senhora do Rosário em Silvianópolis é heterogêneo e, com isso, disparidades emanam nas territorialidades festivas. Logo, foram realizadas entrevistas com o público festivo buscando entender como os espaços são vivenciados, quais as territorialidades e os momentos festivos configuram-se mais atraentes para eles.

A festa com mais de dois séculos de existência se faz repleta de acontecimentos importantes que culminaram no que ela é hoje. Mas será que o público presente conhece a história festiva? No gráfico 1, cerca de $38 \%$ dos entrevistados falaram conhecer a história da festa, $35 \%$ responderam não e $27 \%$ disseram conhecer pouco.

Conforme externalizado no gráfico 1, a maior parte dos entrevistados conhecem a história da festa de Silvianópolis. Contudo, quando problematizada sobre as questões referentes aos conflitos muitos desconhecem, associam a história da festa às manifestações culturais, principalmente às congadas, distinguindo pouco os aspectos econômicos e políticos atrelados ao seu meio.

Conforme já aludido há grande heterogeneidade na população festiva, por isso houve o intuito de compreender a visão do público presente sobre os princípios religiosos da festa. Por este motivo foi perguntado de acordo com o conhecimento do entrevistado sua percepção sobre a religiosidade presente na manifestação; por volta de $86 \%$ dos entrevistados veem a festa como religiosa e $14 \%$ não enxergam a festa como religiosa. As respostas ligadas aos $14 \%$ estão associadas a diversos motivos sendo um deles o uso da territorialidade festiva para 
EM

o lazer, desconhecendo, assim, os símbolos e espaços sagrados existentes na mesma. Outro motivo levantado foi relacionado a igreja central não permanecer aberta durante grande parte dos dias festivos, fazendo com que muitos associassem a não sacralidade do momento. Houve também entrevistados analisando a festa mais ligada ao cenário cultural do que religioso.

Gráfico 1 - Conhecimento da história da festa de Nossa Senhora do Rosário pelo público presente, 2019.

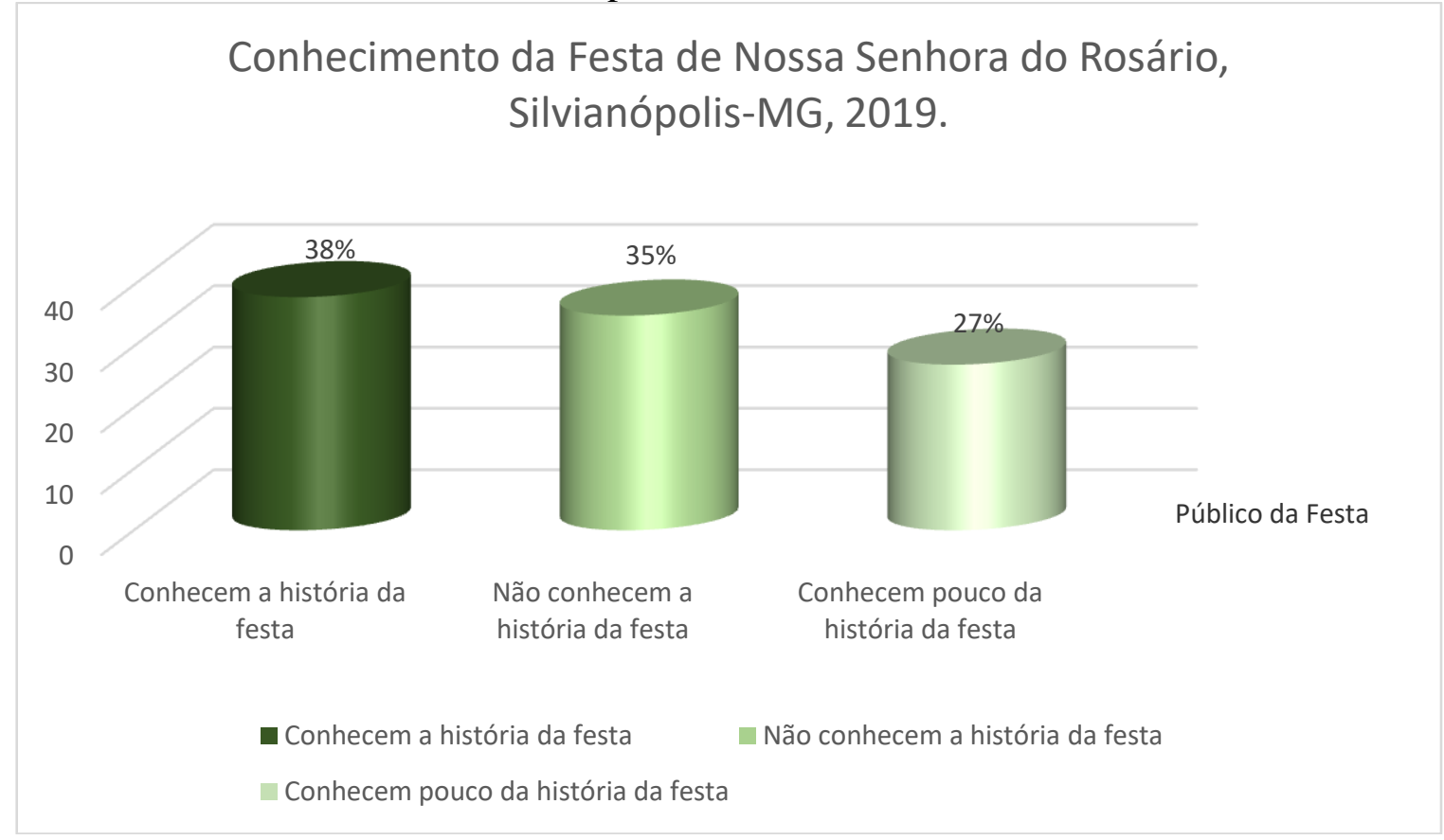

Fonte: Organização dos autores (junho de 2019).

Entretanto, é sabido que o catolicismo popular foi durante muito tempo entendido pelo catolicismo oficial como profano, não tendo suas manifestações respeitadas e muitas vezes sendo desapropriado de suas sacralidades, tanto materiais como imateriais, uma espécie de privatização do sagrado pela hegemonia do catolicismo oficial conhecida como "romanização". Todavia, o sagrado não tem dono e se constitui atrelado ao espaço-tempo de um lugar (CORRÊA e ALVES, 2020). Quando questionado aos 86\% dos entrevistados o porquê de a festividade ser religiosa, houve uma infinidade de alegações sendo as mais frequentes entre elas: a fé, a Congada, o reinado, os santos padroeiros da festividade e a tradição do catolicismo popular.

Foi levantado uma interrogação sobre qual momento é o mais esperado pelos participantes, sendo a maior atração festiva para eles. Como consequência, diversas respostas foram registradas: a Congada foi a mais citada, seguida pelo reinado e a subida e descida do mastro. Sem dúvidas, os momentos referenciados são repletos de hierofanias e festa sem 
EM

QUESTÃO

Congada não há. Além do mais, outra resposta frequente foi direcionada ao encontro de amigos e o retorno à cidade natal - mostrando mais uma característica festiva. Observa-se que os pontos referenciados estão relacionados mais ao espaço sagrado, contudo também há apontamentos direcionados ao espaço profano.

Os ternos de congadas, moçambiques e caiapós são os alicerces festivos, foi perguntado ao público presente se conheciam os ternos de congadas ou se já participaram de algum. Por volta de $87 \%$ dos entrevistados falaram conhecer a congada; $9 \%$ não conhecem e $4 \%$ conhecem muito pouco conforme o gráfico 2 .

Gráfico 2 - Conhecimento sobre as Congadas da festa de Nossa Senhora do Rosário pelo público presente, 2019.

\section{Conhecimento das Congadas da Festa de Nossa Senhora do Rosário, Silvianópolis-MG, 2019.}

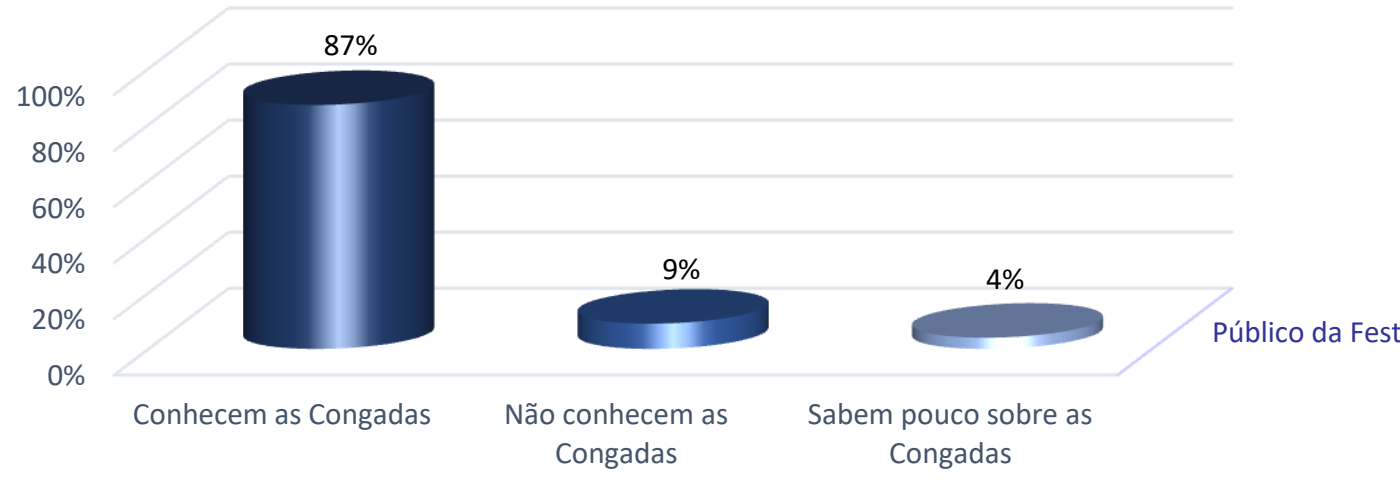

- Conhecem as Congadas

— Não conhecem as Congadas

Sabem pouco sobre as Congadas

Fonte: Organização dos autores (junho de 2019).

É perceptível no gráfico 2, a maioria dos entrevistados conhecem as congadas. Durante as entrevistas, ficou compreensível que os moradores de outros municípios majoritariamente adolescentes e jovens não conheciam as congadas. Além disso, das 52 entrevistas $23 \%$ já participaram de um terno de congada e $77 \%$ não participaram. Sendo assim, é compreensível que a grande parte do público festivo embora conheça as congadas não são muitos os que já se envolveram de forma assídua nos ternos.

Logo é nítido a pluralidade do público presente, resultando nas múltiplas representações festivas. Assim, através dos elementos internos e externos são notáveis as mutações convergindo para as transformações culturais. Mutações essas que ao longo do 
EM

QUESTÃO

V.14 N. $02 \downarrow 2021$

pág. 185-205

espaço-tempo transformaram a festa no que ela é hoje e constituem hodiernamente novas configurações territoriais emanando territorialidades que ainda estão em formação perante a outras já consolidadas.

\section{Considerações finais}

A presente pesquisa está em construção, por isso as considerações aqui apresentadas condizem a um trabalho em desenvolvimento. A tradicional Festa de Nossa Senhora do Rosário com seus mais de dois séculos está em constante mutação, sendo assim há territorialidades ainda em consolidação mantendo o jogo de poderes vivo no espaço e tempo festivo. Ademais, diferentemente das outras festividades populares existentes no sul de Minas Gerais, o catolicismo popular mantém seu protagonismo e domínio sobre a manifestação. Por conseguinte, consegue desvencilhar-se do poder hegemônico do catolicismo oficial e consolidar uma territorialidade festiva mais diversa onde o sincretismo religioso é presente através dos ternos de Congadas, Moçambiques e Caiapós. O tempo festivo e seus rituais fundam uma volta às origens conforme mostrou Eliade (1962), sendo de grande importância sua realização no tempo cronológico e/ou kairológico (ROSENDAHL, 2018).

As múltiplas territorialidades existentes na festividade mostram o quanto o público hodierno é distinto. O sagrado possui elementos que em simbiose com o profano configuram as atuais condições, podendo expressar conflitos em suas bases. O indivíduo religioso percebe a festividade de forma diferente, para ele há elementos religiosos e sagrados; em contrapartida o indivíduo profano tem sua percepção atrelada a outras referências espaciais destituídas de sacralidade (ELIADE, 1962). O cenário festivo atual traz grande protagonismo aos moradores do município, à Associação de Caridade Nossa Senhora do Rosário e aos festeiros, formulando a força administrativa e abstrata da festa.

Por conseguinte, resistir é necessário, a cultura como elemento mutável traz modificações em seu centro contribuindo para a metamorfose festiva a deixando mais atrativa para uma gama de públicos, contudo há um preço posteriormente podendo resultar na perda territorial. Os rituais (re)passados por gerações ainda resistem; hereditário e através da oralidade formam novos congadeiros e congadeiras, fiéis fardados e devotos de Nossa Senhora do Rosário, São Benedito e Santa Efigênia - santos elevados aos status de padroeiros populares. 
Todo contexto existente no desenvolver da festividade mostrou a investida construída no campo do poder para a manutenção do status quo religioso. Como mostrou Rosendahl (2003) quando se trata de religião ela nunca é compreendida por si só; há elementos políticos, econômicos e sociais em sua abordagem. Sendo assim, a festa popular relacionada a uma santa do povo, ligada a uma comemoração de descendentes de escravizados ser a maior festa do município e não necessitar de membros eclesiásticos para acontecer é uma afronta para o catolicismo oficial. Assim como aquilombados eram perigosos em uma sociedade escravagista, populares autônomos em seu credo se tornaram um problema para uma instituição pouco renovada e adepta do alicerce hierocrático. Logo, é perceptível as diversas nuances da festa que através de um trabalho qualitativo e quantitativo, resultou na compreensão da singularidade presente no espaço-tempo festivo.

\section{Referências}

ARENDT, H. O que é política? [editora, Ursula Ludz]; tradução Reinaldo Guarany. - $7^{\circ}$ ed. - Rio de Janeiro: Bertrand Brasil, 2007.

ALVES, F, D. Cidades Pequenas no Sul de Minas Gerais: Ruralidades Presentes no Território. In: FERREIRA, M, M; VALE, A, R(Org). Dinâmicas Geográficas no Sul de Minas Gerais. 1. ed. - Curitiba: Appris, 2018.

BONNEMAISON, J. Viagem em Torno do Território. In: CORRÊA, R, L. ROSENDAHL, Z. (org). Geografia Cultural: um século (3). - Rio de Janeiro: EdUERJ, 2002.

BOSI, E. Cultura de massa e cultura popular: leitura de operárias; apresentação de Dante Moreira Leite, prefácio de Otto Maria Carpeaux. Petrópolis, Vozes, 1986.

CLAVAL, P. A Geografia Cultural. Tradução: Luiz Fugazzola Pimenta, Margareth de Castro Afeche Pimenta. - 4. ed. Ver. - Florianópolis: Ed. Da UFSC, 2014.

CORRÊA, J, S; ALVES, F, D. A Questão Territorial da Festa de São Benedito em MachadoMG. Geographia Opportuno Tempore, Londrina, v.3, n.2, p. 165-178, 2017.

CORRÊA, R, L. Espaço e Simbolismo. In: CASTRO, I, E; GOMES, P, C, C; CORRÊA, R, L(org). Olhares Geográficos: modos de ver e viver o espaço. - Rio de Janeiro: Bertrand Brasil, 2012.

CORRÊA, J, S. Religião e Poder: a manifestação do catolicismo popular no Sul/Sudoeste de Minas Gerais. Geographia Opportuno Tempore, Londrina, v.5, n. 2, p. 104-121, 2019.

CORRÊA, J, S; ALVES, F, D. Ruralidade, Paisagem e Territorialidade: a Festa de São Benedito em Machado-MG. In: ALVES, F, D; AZEVEDO, S, C(org). Análise Geográficas 
sobre o Território Brasileiro: dilemas estruturais à COVID. Alfenas-MG, Editora Universidade Federal de Alfenas, 2020.

DARDEL, E. O Homem e a Terra: natureza da realidade geográfica. Tradução: Werther Holzer. - São Paulo: Perspectiva, 2015.

DEFFONTAINES, P. Geographie et Religions. $4^{\circ}$ ed, Gallimard. France, 1948.

DOMINGUES, A, S. Cultura e Identidade: Festa da igreja para os padres e a Festa de Nossa Senhora do Rosário para as pessoas do Cativeiro. Anais do XXVI Simpósio de História ANPUH. São Paulo, julho de 2011.

ELIADE, M. O sagrado e o profano. A essência das religiões. Edições livros do Brasil. Lisboa, 1962.

FOUCAUlT, M. Microfísica do Poder. Organização, introdução e revisão técnica de Roberto Machado. - $6^{\circ}$ ed. - Rio de Janeiro/ São Paulo: Paz e Terra, 2017.

GIDDENS, A. SUTTON, P. Conceitos Essenciais da Sociologia. São Paulo: Editora Unesp, 2016.

FREYRE, G. Casa-grande \& Senzala. Ilustrações Cícero Dias e Antonio Montenegro $39^{\circ}$ ed - Rio de Janeiro: Record 2000.

HAESBAERT. R. Territórios Alternativos. Editora Universidade Federal Fluminense. Rio de Janeiro - RJ, 2006.

HOLZER, W. Método Fenomenológico: humanismo e a construção de uma nova geografia. In: ROSENDAHL, Z; CORRÊA, R. L. (org). Temas e Caminho da Geografia Cultural. Rio de Janeiro: edUERJ, 2010.

IBGE. Enciclopédia dos Municípios Brasileiros. Volume XXVII, Rio de Janeiro, 1959.

IBGE - Instituto de Geografia e Estatística. Cidades.[online]. Disponível na internet via WWW URL: https://cidades.ibge.gov.br/brasil/mg/silvianopolis/panorama. Acessado em 01 de maio de 2020 , às $20 \mathrm{~h}$ e $30 \mathrm{~min}$.

LIMA, M. Uso da Entrevista na Pesquisa Empírica. In: ABDAL, A, Et al. Métodos de Pesquisas Sociais: Bloco Qualitativo. Sesc São Paulo/ CEBRAP. São Paulo, 2016.

LEERS, B. Catolicismo Popular e Mundo Rural. Editora Vozes Ltda. Petrópolis-RJ, 1977.

LEMOS, G, S. O conceito de Conflito nos Estudos Sociolinguísticos, internacionais e narrativos: uma revisão epistemológica e teórica-análitica. Dilemas, Rev. Estud. Conflito Controle Soc. - Rio de Janeiro - Vol. 14 - no 2 - MAI-AGO 2021 - pp. 425-440

LUCHIARI, M, T, D, P. A (Re)Significação da Paisagem no Período Contemporâneo. In: ROSENDAHL, Z; CORREAA, R, L. (org). Paisagem, Imaginário e Espaço. - Rio de Janeiro: EdUERJ, 2001. 
MALINOWSKI, B. Uma Teoria Científica da Cultura. Zahar Editores, Rio de Janeiro, 1975

RAFFESTIN, C. Por Uma Geografia do Poder. Ed. Ática S.A, 1993.

RIBEIRO, D. O Povo Brasileiro: a formação e o sentido do Brasil. - 3. Ed. - São Paulo: Global, 2015.

ROSENDAHL, Z. CORRÊA, R, L. Espaço, Cultura e Religião. In: CORRÊA, R, L; Z, ROSENDAHL (org). Introdução à Geografia Cultural - Rio de Janeiro: Bertrand Brasil, 2003.

ROSENDAHL, Z; CORRÊA, R, L. Espaço e religião: uma abordagem geográfica. - $2^{\circ}$ edição - Ed Uerj, Rio de Janeiro 2002.

ROSENDAHL, Z. História, Teoria e Método em geografia da Religião/ Zeny Rosendahl. Espaço e Cultura, UERJ, RJ, N. 31, p. 24-39, JAN./ JUN DE 2012(b).

ROSENDAHL, Z. Primeiro a Devoção, Depois a Obrigação: estratégias espaciais da Igreja Católica no Brasil de 1500 a 2005. - Rio de Janeiro: EdUERJ, 2012(a).

ROSENDAHL, Z. O Sagrado e o Espaço. In: CASTRO, Iná Elias, GOMES, Paulo César da Costa. CORRÊA, Roberto Lobato (Orgs). Explorações Geográficas: percursos no fim do século. $2^{\mathrm{a}}$ ed. Rio de Janeiro: Bertrand Brasil, 2006.

ROSENDAHL, Z. Território e Territorialidade: uma proposta geográfica para o estudo da religião. In: CORRÊA, R, L. ROSENDAHL, Z. (org). Geografia Cultural: uma antologia, volume II/ organização, Roberto Lobato Corrêa, Zeny Rosendahl. Rio de Janeiro: EdUERJ, 2013.

ROSENDAHL, Z. Manifestações da Cultura no Espaço. Ed. Uerj, 1999.

ROSENDAHL, Z. Tempo e Temporalidade, espaço e espacialidade: a temporalização do espaço sagrado. In: ROSENDAHL, Z. Uma procissão na Geografia. - Rio de Janeiro: EdUERJ, 2018.

SAQUET, M, A. Por uma Abordagem Territorial. In: SAQUET, M, L. SPOSITO, E, S. (org). Territórios e Territorialidades: teorias, processos e conflitos. 2.Ed.. - Rio de Janeiro: Consequência Editora, 2015.

SOUZA, M, L. Os Conceitos Fundamentais da pesquisa Sócio-espacial. - 2015. $2^{\circ}$ ed. Rio de Janeiro: Bertrand Brasil, 2015(b).

SOUZA, M, J. Reinado e Poder no Sul das Minas Gerais. - Belo Horizonte. Mazza Edições, 2015(a).

SÜSS, G, P. Catolicismo Popular no Brasil: tipologia e estratégia de uma religiosidade vivida. Loyola, São Paulo, 1979. 
EM

QUESTÃO

V.14 N. $02 \bullet 2021$

pág. $185-205$

OLIVEIRA, J, O. Geografia, religião e mídia: novas interfaces do sagrado na era hipermoderna. REVER. São Paul. V.19, N.3, set/dez 2019.

TUAN, Y. Espaço e Lugar: A perspectiva da experiência. Tradução: Lívia de Oliveira. Londrina: Eduel, 2013.

Artigo recebido em 10-03-2021

Artigo aceito para publicação em 21-09-2021 